Elman, R. and Weiner, D. O. (1939). J. Amer. med. Ass. 112, 796.

Elman, R., Weiner, D. O. and Bradley, E. (1942). Ann. Surg. 115, 1160.

Gaunt, W. E. (1944). Nutr. Abstr. Rev. 13, 501.

Hartmann, A. F., Lawler, H. J. and Meeker, C. S. (1944). J. Pediat. 24, 371.

Hill, L. W. (1941). J. Amer. med. Ass. 116, 2135.

Hopps, H. C. and Campbell, J. A. (1943). J. Lab. clin. Med. 28, 1203.

Krishnan, K. V., Narayanan, E. K. and Sankaran, G. (1944). Indian med. Gaz. 79,160 .

Lipscomb, F. M. (1945). Lancet, 249, 313.

Lucido, J. (1940). Ann. Surg. 111, 640.

Messinger, W. J. (1943). Archi. intern. Med. 72, 91.

Narayanan, E. K. and Krishnan, K. V. (1944). Indian med. Gaz. 79, 158.

Neumeister, R. (1889). S.B. phys.-med. Ges. Würzburg, p. 64.

Olmsted, W. H., Harford, C. G. and Hampton, S. F. (1944). Arch. intern. Med. $73,341$.

Shohl, H. T. (1943). J. clin. Invest. 22, 257.

Taylor, F. H. L., Levenson, S. M., Davidson, C. S., Browder, N. C. and Lund, C. C. (1943). Ann. Surg. 118, 215.

Vaughan, J., Dent, C. and Pitt-Rivers, R. (1945). Proc. R. Soc. Hed. 38, 395.

\title{
Use of Isotopic Tracers in the Study of Protein Metabolism
}

Mr. H. D. Griffith (Department of Natural Philosophy, University of
Aberdeen)

\section{The Technique and its Limitations}

Since the first application of isotopic analysis to biological problens by Hevesy (1923) in collaboration with Paneth, isotopes of a very wide range of elements have become available (see Seaborg, 1944). Those which have been used to study protein metabolism include stable isotopes of hydrogen, carbon, nitrogen, oxygen and sulphur, and radio-active isotopes of carbon, sulphur and phosphorus. An experiment by Foster, Schoenheimer and Rittenberg (1939), in which $\mathbf{N}^{15}$ was used, may be quoted in illustration of the sort of technique involved. The problem concerned the fate of ingested ammonia. In normal ammonia, as in all normal nitrogen compounds, 0.368 per cent. of the nitrogen atoms are of the "heavy" species; by special methods, discussed later, a sample of ammonium citrate was prepared containing 1.578 per cent. of its nitrogen as $\mathrm{N}^{15}$, that is, $1 \cdot 21$ per cent. "excess" $\mathrm{N}^{15}$. This material was fed to rats; the urinary bippuric acid was isolated, and was found to contain 0.045 per cent. excess $\mathrm{N}^{15}$, i.e., 0.413 per cent. of its nitrogen was $\mathrm{N}^{15}$. The conclusion was that 0.045 out of 1.21 parts of ingested ammonia, or about 3 to 4 per cent., was excreted as hippuric acid. Two great advantages of the isotopic technique should be noted. It was not necessary to isolate all the hippuric acid excreted; all that was required was to secure a small pure specimen, sufficient to yield about $1 \mathrm{mg}$. of total nitrogen; moreover, unequivocal information was obtained as to the fate of the ammonia which was fed, though most of the hippuric acid found in the urine came from other sources.

If a radio-active isotope is employed, the technique is similar, but detection and estimation of the isotope in the final product is by physical tests for the emitted radiation using particle counters or ionization 
chambers (Gaunt, Griffith and Irving, 1942). Difficulties, however, may arise in compensating for the decay of the isotopes during the period of the experiment if the ingested radio-compound is not entirely free from radio-active contamination (Smith and Cowie, 1941).

Two main assumptions underlie such methods of analysis. The first is that a molecule containing a "heavy" isotope reacts in all respects as would one containing only "normal" atoms. In other words, we assume that if we introduce a spy into the normal molecular population, other molecules are completely unable to discriminate between the spy and an honest citizen. The soundness of this assumption has been tested by Schoenheimer and Rittenberg (1939), who found that the isotopic composition of nitrogen specimens isolated from air, from protein and from gas-works ammonia was identical. Even in the extreme case of deuterium, which has double the mass of its simpler isotope hydrogen, Dole $(1936,1,2)$ has found no evidence of difference of isotopic composition in hydrogen obtained from honey, cholesterol, benzene or water. On the other hand Nier and Gulbransen (1939) have found some evidence of discrimination between the carbon isotopes $\mathrm{C}^{12}$ and $\mathrm{C}^{13}$. On general grounds, when we consider the great difficulties which must be overcome in modifying appreciably the normal isotopic composition of an element, for instance, by exchange reactions, the expectation of finding appreciable discrimination during the processes of normal metabolism would appear to be slender, though the chance may be substantially greater when the isotopes involved are deuterium and hydrogen.

A second assumption made when radio-active isotopes are employed is that the radiation released in the body of the subject is insufficient to produce appreciable physiological change. Since some concentration in special tissues may occur, as when radio-phosphorus is concentrated in bone, the results of final analysis must be reviewed very critically in conjunction with the known data as to the threshold of various tissues for radiological damage (Evans, 1941, 1944). These considerations set a limit to the amount of a radio-isotope which may be introduced, and indirectly may put stringent demands on the counters or electroscope systems used in the final analysis. In the matter of ultimate sensitivity, calculations by Loofbourow (1940), based on work by Chaikoff, showed that the least amount of phosphorus, present as hexose monophosphate, which could be detected may be as small as four-thousandths of a microgram; this figure assumes that in the radio-phosphorus preparation employed the proportion of $\mathrm{P}^{31}$ to $\mathrm{P}^{32}$ is not above $100,000: 1$.

The principal limitation of technique when stable isotopes are employed arises from the "dilution" with material of normal isotopic composition, which the ingested sample undergoes in the body of the subject. If this dilution is excessive the proportion of the tracer isotope falls below the sensitivity of the detecting instrument and the presence of the tracer is no longer demonstrable. The allowable dilution varies widely acording to the isotope used and the technique employed, but is often of the order of 1 in 30,000 .

\section{Production and Availability of Isotopes}

Very many atomic species can be synthesized by bombarding appropriate stable atoms with particles of suitable energy or with $\gamma$ ray quanta. vor. 4,1946$]$ 
Especially powerful projectiles are deuterons and neutrons. The projectile enters the nucleus of the target atom, which then generally disrupts in a manner comparable with the spontaneous disruption of uranium, giving rise to a new nucleus which may be stable or unstable to a varying degree. In illustration of some types of nuclear reactions, the following may be quoted. Impact of $\alpha$ particles on beryllium gives a convenient source of neutrons, realized by admitting radon into a tube containing powdered beryllium. Stable carbon is the other product:

$$
\mathrm{Be}_{4}^{9}+\mathrm{He}_{2}^{4} \rightarrow \mathrm{C}_{6}^{12}+\mathrm{n}_{0}^{1} \text {. }
$$

Sulphur bombarded by neutrons from such a source is converted to radio-phosphorus:

$$
\mathbf{S}_{16}^{32}+\mathbf{n}_{0}^{\mathbf{1}} \rightarrow \mathbf{P}_{15}^{32}+\mathbf{H}_{1}^{1} .
$$

The ejected particles, neutron or proton, leave with great kinetic energy, often of the same order as the energy of natural $\alpha$ particles. The radio-phosphorus $\mathbf{P}_{15}^{32}$ is isotopic with "normal" phosphorus $\mathbf{P}_{15}^{31}$, but its nucleus contains an extra neutron and is unstable, having a half life of $14 \cdot 3$ days. It disrupts with ejection of an electron (a $\beta$ particle); the product is a stable sulphur nucleus:

$$
\mathbf{P}_{15}^{32} \rightarrow \mathrm{S}_{16}^{32}+\beta_{-1}^{0} .
$$

An alternative method to obtain radio-phosphorus is to bombard stable phosphorus with fast deuterons:

$$
\mathrm{P}_{15}^{31}+\mathrm{D}_{1}^{2} \rightarrow \mathrm{P}_{15}^{32}+\mathrm{H}_{1}^{1}
$$

The product so obtained is identical with that resulting from the technique first described. In either case, the radio-phosphorus present in the target can be oxidized to phosphoric acid and then used for biological studies either as phosphate or after conversion to any other appropriate derivative. An alternative method, devised by Szilard and Chalmers (1934), isolates the reaction product by utilizing the great kinetic energy which new nuclei possess at the instant of formation. If the parent atom is held in, say, a hydrocarbon derivative, the reaction product will be thrown out from the hydrocarbon and a large proportion may be readily reclaimed in the elementary or ionic form.

As a further example one can take the case of the radio-carbon $\mathrm{C}_{6}^{14}$, with a period known to be greater than 25 years, which is produced by action of slow neutrons on nitrogen:

$$
\mathrm{N}_{7}^{14}+\mathbf{n}_{0}^{1} \rightarrow \mathrm{C}_{6}^{14}+\mathrm{H}_{1}^{1} .
$$

It is conveniently obtained as a by-product by introducing ammonium nitrate or urea into the protective water with which technical or therapeutic cyclotrons are surrounded (Ruben and Kamen, 1941). The uranium-graphite piles employed to liberate sub-atomic energy by fission of the uranium nucleus are very powerful neutron sources. Such large amounts of radio-isotopes are produced as an inevitable by-product in all objects in their neighbourhood as to constitute a serious hazard to the health of the operators (Smyth, 1945). We may anticipate that supplies of biologically useful isotopes from these sources will shortly become available. 
It must be emphasized that the chemical symbols in nuclear equations are used to represent the nuclear structure without reference to the electronic configuration surrounding the nucleus. This latter adjusts itself to the nuclear charge within an extremely short time following change of nuclear composition.

When the content of tracer atoms in the material reclaimed from the subject's body is to be estimated, particle counters or an ionization chamber and electroscope can be employed. The counter can be made more sensitive than the electroscope by a factor of twenty, but only at some sacrifice of speed of working (see Evans and Mugele, 1936; Evans, 1944; Lifschutz, 1939; McKay, 1941).

\section{Use of Stable Isotopes}

The proportion of wanted atoms in a good preparation secured by artificial bombardment is unlikely to exceed one in a thousand and may be as small as one millionth part of this; these quantities suffice for studies with radio-active tracers when highly sensitive electrical methods of detection can be applied. Stable isotopes, however, cannot be produced by nuclear bombardment in quantities sufficient for tracer studies because of the relative insensitivity of available methods of detection. It has therefore been necessary to devise methods for concentrating one component of the mixture of isotopes of which normal specimens of most "natural" elements consist.

Such methods must utilize some consequence of the difference in mass of the isotopic species. The most direct is high speed centrifugation; others are based on the difference of mean velocity of thermal agitation, difference in diffusion rate, chemical exchange reactions, or vapour pressure. Excluding the well known special case of deuterium, which is most conveniently concentrated by electrolysis of water (Lewis, 1933), the most widely applicable process is that of thermal diffusion (Urey, 1941). If different parts of a vessel containing a mixture of two gases are maintained at different temperatures, a diffusion process ensues which makes the mixture non-uniform; an excess of the lighter component accumulates in the hotter part of the vessel until eventually a concentration gradient is established such that ordinary diffusion suffices to maintain a dynamic equilibrium. As Chapman and Cowling (1939) have shown, this is a consequence of the generalized kinetic theory of gases and occurs in all cases except that in which the repulsive forces between the molecules exactly satisfy a fifth power law. The theory was verified. by Chapman and Dootson (1917) and by Ibbs and Grew (1931) for artificial mixtures of gases, and first applied to separation of isotopes by Clausius and Dickel $(1938,1,2)$. As developed by them and further by Nier (1940), the apparatus consists of two vertical concentric cylindrical metal tubes about 24 feet long, having a narrow annular space between them. The inner one is kept at $300^{\circ} \mathrm{C}$. while the outer is water cooled. A combination of thermal diffusion and convection occurs in any gas mixture introduced into the annular space, and results after some hours in an equilibrium in which the heavier component shows relative concentration at the base of the column. Working with normal methane which contains 1.1 per cent. of its carbon as $\mathrm{C}_{6}^{13}$ uniformly distributed, the proportions can be altered so as to give, with the simple apparatus vor.. 4,1946 ] 
of one column, specimens of methane in which the proportion of $\mathbf{C}_{6}^{13}$ is raised to ten times the normal; the method is applicable to all elements which give gaseous compounds, or which are themselves gaseous, and has been used with carbon, oxygen, nitrogen and sulphur.

Methods involving fractional distillation, developed into multi-stage processes of the cascade type, have been devised (Fenske, Tongberg and Quiggle, 1934) to utilize the difference in vapour pressure, of the order of 0.5 per cent., between similar compounds of two isotopes. Exchange reactions of, say, ammonia gas with its aqueous solution offer similar possibilities for securing the concentration of the heavy and less mobile $\mathrm{N}^{15}$; an apparatus in which exchange processes are made to occur repeatedly and in which counter-current flow of the progressively enriched and progressively impoverished fractions is automatically established has been described by Thode and Urey (1939). By these methods, concentrates sufficiently enriched for biological studies of nitrogen as ammonia, of carbon as carbon dioxide, and of sulphur as sulphur dioxide, should shortly be available at a cost for power and labour of the order of $\mathfrak{1 3}$ per g. (Urey, 1941). Stronger concentrates, up to 100 per cent. $\mathrm{N}^{15}$ or 50 per cent. $\mathrm{C}^{13}$ are available if required (Taylor, 1939).

The detection of stable isotopes in the reclaimed material is best effected by the use of the mass spectrograph (Nier, 1940). The specimen, say an amino-acid, is decomposed chemically and the liberated nitrogen introduced into an evacuated space traversed by an electron beam. Here its atoms are converted to ions by impact and these are caught up by an electric field and projected through a slit into a magnetic field; in this they follow circular paths of radii dependent on their mass, and the various atomic species present, therefore, reach different portions of a target plate. The currents collected at the target are, therefore, a measure of the number of ions of the particular atomic species reaching it, and the relative proportions of various species present in the sample introduced is directly given by the ratio of the collected currents. A change of 0.003 per cent. in the proportion of $\mathrm{N}^{15}$ is detectable with specimens of nitrogen amounting to $1 \mathrm{mg}$.; the analysis of a specimen takes about 45 minutes. Analysis for carbon, oxygen, sulphur, or deuterium follows on similar lines. It is a particular advantage of analysis by the mass spectrograph that the method does not demand the elaborate purification of the specimen which is essential if, say, deuterium is to be estimated from the determination of the density or refractive index of combustion water.

Whenever an isotope is built into any molecule for tracer work, attention must be paid to the possibility of its loss by exchange reactions with the normal element in neighbouring molecules. Deuterium, for instance, is useless in amino-, carboxyl- or hydroxyl-groups since it exchanges immediately with hydrogen from the body fluids. It is, however, very stable if linked to carbon. Nitrogen in amino-groups is stable, andresists exchange with nitrogen of ammonia even at high temperatures. Since carbon is unlikely to exchange, it should prove to be a particularly versatile and valuable tool in tracer research (Keston, 1944). 
REFTRENCES

Chapman, S. and Cowling, T. G. (1939). Mathematical Theory of Non-uniform Gases, p. 252. Cambridge University Press.

Chapman, S. and Dootson, F. W. (1917). Phil. Mag. 33, 248.

Clausius, K. and Dickel, G. (1938, 1). Naturwissenschaften, 26, 546.

Clausius, $K$. and Dickel, G. $(1938,2)$. Naturwissenschaften, 27, 487.

Dole, M. $(1936,1)$. J. Amer. chem. Soc. 58, 580.

Dole, M. $(1936,2)$. J. Amer, chem. Soc. 58, 2552.

Evans, R. D. (1941). J. appl. Phys. 12, 262.

Evans, R. D. (1944). Medical Physics. [Ed. Glasser]. p. 643. New York: The Year Book Publishers.

Evans, R. D. and Mugele, R. A. (1936). Rev. sci. Instrum. 7, 441.

Fenske, M. R., Tongberg, C. O. and Quiggle, D. (1934). Industr. Engng Chem. 26, 1169.

Foster, G. L., Schoenheimer, R. and Rittenberg, D. (1939). J. Jiol. Chem. 127, 321.

Gaunt, W. E., Griffith, H. D. and Irving, J. T. (1942). J. Physiol. 100, 372.

Hevesy, G. V. (1923). Biochem. J. 17, 439.

Tbbs, T. L. and Grew, K. E. (1931). Proc. R. phys. Soc. Lond. 43, 142.

Keston, A. S. (1944). Medical Physics. [Ed. Glasser]. p. 658. New York: The Year Book Publishers.

Lewis, G. N. (1933). J. Amer. chem. Soc. 55, 1298.

Lifschutz, H. (1939). Rev. sci. Instrum. 10, 21.

Loofbourow, J. R. (1940). Rev. mod. Phys. 4, 267.

MeKay, H. A. C. (1941). Rev. sci. Instrum. 12, 104.

Nier, A. O. (1940). Phys. Rev. 57, 31.

Nier, A. O. and Gulbransen, E. (1939). J. Amer. chem. Soc. 61, 697.

Ruben, S. and Kamen, M. D. (1941). J. appl. Phys. 12, 311.

Schoenheimer, R. and Rittenberg, D. (1939). J. biol. Chem. 127, 285.

Seaborg, G. T. (1944). Rev. mod. Phys. 16, 3.

Smith, J. H. C. and Cowie, D. B. (1941). J. appl. Phys. 12, 78.

Smyth, H. D. (1945). Atomic Energy, p. 70. London: H.M.S.O.

Szilard, L. and Chalmers, W. (1934). Nature, Lond., 134, 462.

Taylor, H. S. (1939). Nature, Lond., 144, 8.

Thode, H. G. and Urey, H. C. (1939). J. ehem. Phys. 7, 36.

Urey, H. C. (1941). J. appl. Phys. 12, 270.

\section{Modern Methods of Studying Protein Metabolism}

\section{Dr. J. N. Davidson (National Institute for Medical Research, Hampstead, London, N.W.3)}

The most important advance of recent years in methods of studying protein metabolism has undoubtedly been the application of the use of isotopes for following metabolic patbways. For this purpose the nitrogen isotope $\mathbb{N}^{15}$ has been extensively employed by Schoenheimer (1942) and his colleagues, but other isotopes such as deuterium, $\mathrm{C}^{13}$ and $\mathrm{S}^{34}$ have also been used on a smaller scale.

The isotope $\mathrm{N}^{15}$ normally occurs to an extent of 0.368 per cent. in the nitrogen of inorganic and organic compounds and of the air, and the cells of animal and plant tissues are therefore accustomed to both $\mathrm{N}^{14}$ and $\mathrm{N}^{15}$ and treat them indiscriminately. Hence a physiological compound in which the concentration of $\mathrm{N}^{15}$ has been artificially raised will not constitute a substance foreign to the organism. The carbon-nitrogen linkage of amino- and guanido-compounds is relatively stable in vitro so that loss of $\mathrm{N}^{15}$ from an amino-acid will oceur only when chemical reactions take place at the amino-group (Schoenheimer and Rittenberg, 1939; Keston, Rittenberg and Schoenheimer, 1939).

voL. 4,1946 ] 